\title{
Portfólio digital: o blog no recurso pedagógico no ensino superior
}

\section{Digital portfolio: the blog on the pedagogical use in higher education}

\author{
André Azevedo da Fonseca ${ }^{1}$
}

\section{Resumo}

O presente artigo propõe uma reflexão sobre a experiência pedagógica realizada com alunos do $1^{\circ}$ período em Comunicação Social, na Universidade de Uberaba (UNIUBE), na disciplina Fundamentos Científicos da Comunicação. A experiência consistiu na aplicação de uma avaliação formativa inspirada na estratégia do portfólio, mas com uma particularidade: o registro do processo de aprendizagem deveria ser feito em um diário virtual (blog). Os estudantes deveriam anotar suas vivências acadêmicas, sob orientação do professor, observando as regras estabelecidas no plano de ensino. O resultado evidenciou que o uso sistemático do blog acadêmico contribuiu para que os alunos se tornassem mais conscientes do desenvolvimento de seus conhecimentos em relação às discussões da disciplina.

Palavras-chave: Avaliação. Portfólio. Diário virtual. Blog.

\begin{abstract}
This paper proposes a reflection on the teaching experience with students performed the 1st period in Social Communication at the University of Uberaba (UNIUBE), in Scientific Foundations of Communication discipline. The experiment consisted in implementing a formative assessment strategy inspired by the Portfolio, but with a peculiarity: the record of the learning process should be done in a virtual diary (blog). Students should write their academic experiences, under the guidance of the teacher, observing the rules of the syllabus. The result showed that the systematic use of academic blog helped students become more aware of the development of their knowledge in relation to discussions of discipline.
\end{abstract}

Keywords: Evaluation. Portfolio. Virtual diary. Blog.

\section{Introdução}

Nas últimas décadas, estudiosos da educação têm direcionado suas atenções mais incisivamente sobre a problemática da avaliação. Como observou Hernandez (2000), entre os educadores progressistas há uma evidente rejeição àquela concepção do saber como "acumulação descontextualizada de informação"; do ensino apenas como "transmissão de mensagens codificadas"; e da aprendizagem como "repetição escrita do conteúdo transmitido pelo professor e pelo material didático". Em uma sociedade complexa e repleta de rápidas transformações, o conhecimento não deve jamais ser tratado como algo estático. Se prosseguir contentando-se com fórmulas solidificadas pela velha tradição, a escola será cada vez mais irrelevante diante da plasticidade do mundo contemporâneo.

\footnotetext{
${ }^{1}$ Doutor em História pela Universidade Estadual Paulista “Julio de Mesquita Filho" (Unesp). Professor no curso de Comunicação Social da Universidade de Uberaba (Uniube). Email: azevedodafonseca@gmail.com
} 
Evidentemente, essa crítica implica em uma reflexão sobre o papel histórico da avaliação. Moulin (2005) observa que as estratégias de avaliação da aprendizagem têm procurado desenvolver processos democráticos, justos, qualitativos e significantes, em vez daquela mensuração pontual da avaliação bimestral. Hernandez (2000) propõe que os educadores façam uma séria reflexão sobre aquela prática avaliativa que concentra toda a tensão e direciona todo o sentido da aprendizagem em exames parciais fragmentados que culminam em um exame final supostamente capaz de medir o grau de aquisição de conhecimentos do aluno. E é nesse contexto de transformações nas concepções de ensino e aprendizagem que, adaptada de um mecanismo usual no mundo das artes, foi desenvolvida uma nova proposta de avaliação do processo de aprendizagem: trata-se do portfólio. Para Hernandez, o portfólio é um:

Continente de diferentes classes de documentos (notas pessoais, experiências de aula, trabalhos pontuais, controle de aprendizagem, conexões com outros temas fora da Escola, representações visuais, etc) que proporciona evidências do conhecimento que foi construído, das estratégias utilizadas e da disposição de quem o elabora em continuar aprendendo. (HERNANDEZ, 2000, p. 100)

Assim, o portfólio constitui-se em uma seleção ordenada do desenvolvimento intelectual do estudante, através da auto-organização de sua produção intelectual no decorrer de um tempo determinado. Essa estratégia promove uma forma de avaliação dinâmica realizada pelo próprio estudante, e mostra-se capaz de evidenciar os caminhos do desenvolvimento do aluno no decorrer do ano. Como observou Vieira (2002), o portfólio é muito mais do que uma mera reunião de trabalhos materiais acondicionados em uma pasta. "Além de selecionar e ordenar evidências de aprendizagem do aluno, ele possibilita também identificar questões relacionadas ao modo como os estudantes e os educadores refletem sobre quais os reais objetivos de sua aprendizagem, quais foram cumpridos, e quais não foram alcançados" (VIEIRA, 2002, p.151).
Essa modalidade de avaliação parece respeitar a vivência educativa enquanto processo, e permite que alunos e professores compreendam o próprio desenvolvimento de sua aprendizagem.

$\mathrm{Na}$ Universidade de Uberaba (Uniube), o Instituto de Formação de Educadores (IFE) vem empregando, há alguns anos, a avaliação através de portfólio nos cursos de Licenciatura. De acordo com documento do IFE, o objetivo da implantação do portfólio era estabelecer "um instrumento que desse espaço à criatividade, à construção e que registrasse o percurso desse processo de construção do saber". (GUSMAN et al., 2002, p. 2). O documento defende, fundamentado na experiência prática, que a avaliação baseada em portfólios estimula o questionamento, a discussão, a suposição, a proposição, a análise e a reflexão.

Fazer Portfólio é estar ciente de ser responsável pela construção de próprio conhecimento e nessa dinâmica, aprender que esse processo será ferramenta de trabalho do futuro profissional: um profissional autor de sua caminhada, capaz de construir as estratégias necessárias a cada momento ou situação, criativo para buscar novas linhas de ação. (GUSMAN et al, 2002, p. 4).

Assim, o presente artigo propõe uma reflexão sobre a experiência pedagógica realizada com alunos do $1^{\mathrm{o}}$ período em Comunicação Social, habilitações Jornalismo e Publicidade \& Propaganda, no segundo semestre de 2005, na Universidade de Uberaba (UNIUBE), em Minas Gerais, na disciplina Fundamentos Científicos da Comunicação. Levando em consideração a evidente proximidade dos alunos de Comunicação Social com as linguagens e instrumentos das mídias digitais, optamos, com o apoio dos coordenadores das habilitações Publicidade \& Propaganda e Jornalismo, Érika Galvão Hinkle e Raul Osório Vargas; e sob orientação da assistente pedagógica do curso de Comunicação, Paulete Mauad, por experimentar uma avaliação inspirada na estratégia do portfólio, mas com uma particularidade fundamental: o registro do processo de aprendizagem deveria ser feito em um diário virtual (blog). 


\section{Os Diários Virtuais (Blogs)}

Blogs, em sua origem, são basicamente diários virtuais na Internet onde os "blogueiros" registram, por conta própria, suas experiências, impressões, pensamentos, comentários, críticas, etc. Uma das peculiaridades dessa modalidade de diário é que, ao contrário dos antigos caderninhos trancados à cadeado onde as meninas escreviam seus inconfessáveis segredos, os blogs são totalmente abertos para consulta on-line, ficam disponíveis em ferramentas de busca na Internet e normalmente contam com uma seção onde os visitantes podem deixar seus comentários. Esse fenômeno nasceu de forma espontânea na Web, até que uma série de empresas passaram a oferecer acesso gratuito à ferramentas de construção e hospedagem dos diários virtuais.

Mesmo com a popularização do Orkut, os blogs continuam multiplicando-se exponencialmente. Uma das grandes vantagens é que essa linguagem digital não exige nenhum conhecimento especial de programação para que seja criado. A interface para a criação de um blog é bastante intuitiva e exige apenas um conhecimento básico dos programas de navegação na Internet. Além disso, em muitas discussões sobre o futuro do webjornalismo, os blogs de notícia parecem prometer inaugurar uma nova modalidade de imprensa, em grande parte devido ao alto grau de liberdade dos autores e à agilidade do texto, além da facilidade de confecção e de acesso ao conteúdo. As atuais discussões giram em torno da viabilidade econômica dessa nova maneira de publicar notícias. Mas há alguns caminhos a serem considerados. Além da venda de publicidade direta em alguns casos, quando a audiência tornase atraente para anunciantes, jornais já passaram a pautar-se ou mesmo reproduzir páginas pessoais de jornalistas - como é o caso de O Estado de S. Paulo, por exemplo, que publica o blog do jornalista Ricardo Noblat. De qualquer maneira, defendemos que é de suma importância experimentar no curso de Jornalismo as possibilidades dessa linguagem em sala de aula, começando já no primeiro período do curso. Por fim, observemos que essa recomendação está expressa nas competências e habilidades que as Diretrizes Curriculares estabelecem para o curso de Comunicação Social, quando o documento do MEC estipula que o comunicador, além de "dominar as linguagens habitualmente usadas nos processos de comunicação, nas dimensões de criação, de produção, de interpretação e da técnica" deve "experimentar e inovar no uso destas linguagens". (BRASIL, 2004)

Quando o educador Ira Shor, em diálogo com Paulo Freire, cunhou a expressão "greve de desempenho", ele se referia ao fato de que, quando os estudantes percebem que a escola pouco diz das coisas que os interessam, eles naturalmente passam a boicotar ao máximo a sala de aula. "Se você vai além do desejo e da capacidade dos estudantes, ou se trabalha fora de sua linguagem e de seus temas, verá os resultados, a resistência deles" (FREIRE; SHOR, 1986, p.73). Assim, a estratégia do uso educacional do blog - uma ferramenta de comunicação largamente utilizada por esta geração - é uma maneira de incluir essa linguagem já presente na cultura digital contemporânea nas atividades pedagógicas do curso. Trabalhar com um meio no qual a atual geração mostra um entusiasmo espontâneo parece uma boa estratégia para respeitar a linguagem cotidiana dos alunos e convidá-los a explorar novas possibilidades de seu próprio universo de expressão.

\section{Procedimentos Iniciais: Plano de Ensino e Folha de Orientações}

A estratégia do uso do blog como instrumento pedagógico na elaboração de portfólios individuais foi expressa textualmente no plano de ensino da disciplina Fundamentos Científicos da Comunicação. Em 2005, a disciplina comportava uma carga horária de 90 horas-aula, sendo 60 presenciais e 30 de atividades não-presenciais, conforme o regimento da universidade. Essas 
30 horas não-presenciais foram aproveitadas no desenvolvimento dos blogs. O Plano de ensino registrava que:

Os alunos deverão criar e desenvolver um diário virtual (blog) na Internet para discutir todos as temas da disciplina. O blog deve conter anotações e comentários originais sobre cada uma das aulas, ligações para outros sítios que tratem de assuntos discutidos em sala de aula, novas referências bibliográficas que possam contribuir com o tema, além de reproduzir todos os trabalhos que forem apresentados nas atividades presenciais. Os alunos deverão visitar periodicamente os diários dos colegas e publicar comentários pertinentes ao tema. Os diários virtuais são criados gratuitamente em vários portais na Internet, e poderão ser produzidos no computador pessoal ou nos laboratórios de informática da Uniube. (FONSECA, 2005).

No trecho do plano de ensino referente à avaliação, registrou-se que:

O diário virtual (blog) servirá como portfólio digital do estudante, ou seja, uma instância de registro e reflexão contínua sobre sua aprendizagem e seu desenvolvimento intelectual. O processo será supervisionado constantemente pelo professor. Serão realizadas, no decorrer do semestre, três vistorias para conferir a manutenção e atualização do diário virtual. A cada uma das vistorias serão concedidos 5 pontos [...], num total de 15 pontos. A vistoria avaliará a atualidade das anotações e o cumprimento dos critérios estabelecidos pelo professor. (FONSECA, 2005)

A pró-reitoria de ensino superior da Uniube determinava que, nos primeiros dias de aula, os alunos deveriam receber uma folha de orientações sobre as atividades não-presenciais. A folha entregue aos estudantes foi a seguinte:

\section{Orientação para a Atividade Não-presencial}

Diário virtual

Passo a passo

1. Crie na Internet um diário virtual pessoal (blog). É muito fácil fazer isso. Para criar seu diário, escolha um serviço gratuito qualquer (Ex.: www. uol.com.br; www.weblogger.com.br; www.theblog. com.br; etc...), faça o cadastro, crie o login, a senha, escolha o modelo do blog e pronto! Ele já pode começar a ser atualizado imediatamente. Escolha um título bem criativo para seu blog e mande brasa! Esse diário virtual servirá para discutir todos os temas da disciplina. Procure cadastrá-lo em alguma ferramenta de busca para deixá-lo disponível para consulta on-line. (Ex.: www.yahoo.com; www. google.com; www.altavista.com; etc.)

2. Informe ao professor, até o dia 10 de agosto, o endereço eletrônico do seu blog. O professor vai visitar seu diário virtual e deixar uma mensagem, confirmando a visita.

3. O blog deve conter anotações e comentários originais sobre CADA UMA DAS AULAS, desde a primeira aula. Ou seja, a partir de suas anotações de sala, escreva um pequeno texto e publique no blog. Você deve "postar", no mínimo, um comentário por aula. Lembre-se: teremos, no semestre, 40 encontros . Portanto, você precisará publicar, no mínimo, 40 "posts". Não é necessário escrever textos muito longos. O padrão é 10 linhas, com fonte Times New Roman, corpo 12, escrito no formato padrão do Word (Folha A4, margens de aproximadamente $3 \mathrm{~cm})$.

4. A cada 5 atualizações/aulas (no mínimo), blog deve conter pelo menos uma ligação para outros sítios que tratem de assuntos discutidos em sala de aula, contendo novas referências que possam contribuir com o tema. Para fazer isso, busque na Internet algum texto cujo tema foi discutido em sala, leia o texto e, se for legal, informe título, um breve resumo e o endereço eletrônico onde está publicado. Se quiser, você pode fazer isso mais vezes.

5. O blog deve conter semanalmente, além do comentário descrito no ítem 4, um comentário sobre pelo menos um artigo publicado no Observatório da Imprensa (www. observatoriodaimprensa.com.br). Este sítio é atualizado sempre às terças-feiras, às $18 \mathrm{hs}$, 
e reúne excelentes artigos sobre jornalismo, publicidade e indústria cultural. É uma leitura IMPRESCINDÍVEL aos comunicadores sociais. Repetindo: quero um comentário por semana sobre um texto publicado no Observatório da Imprensa.

6. O blog deve reproduzir TODOS os trabalhos escritos que forem apresentados nas atividades presenciais, e também, quando for possível, os fotográficos.

7. Os alunos deverão visitar periodicamente os diários dos colegas e publicar comentários pertinentes ao tema. Os endereços ficarão disponíveis na pasta dos ALUNOS na Internet.

8. Os diários virtuais são criados gratuitamente em vários portais na Internet, e poderão ser produzidos no computador pessoal ou nos laboratórios de informática da universidade.

9. O diário virtual (blog) servirá como seu portfólio digital, ou seja, uma instância de registro e reflexão contínua sobre sua aprendizagem e seu desenvolvimento intelectual. O processo será supervisionado constantemente pelo professor.

10. Serão realizadas, no decorrer do semestre, três vistorias para conferir a manutenção e atualização do diário virtual. A cada uma das vistorias serão concedidos 5 pontos, já incluídos nas etapas registradas acima, num total de 15 pontos. A vistoria avaliará a atualidade das anotações e o cumprimento dos critérios estabelecidos pelo professor.

11. Seja criativo! Não é preciso ser sisudo e caretão para fazer um bom texto. É possível ser bem humorado e fazer um trabalho brilhante e inteligente. O importante é que a disciplina seja discutida. Não deixe de incluir fotos e ilustrações para incrementar seu blog.

Divirtam-se, e bom trabalho

André Azevedo da Fonseca

\section{A Experiência com os Blogs}

Imediatamente, entusiasmados com a idéia, mas também pressionados pela primeira vistoria surpresa, os alunos criaram os blogs e enviaram os endereços eletrônicos para o professor, através do sistema interno on-line de comunicação dos alunos. Alguns problemas puderam ser levantados já no momento da exposição da proposta de trabalho em sala de aula. Alguns deles não sabiam o que era um blog, ou como fazê-lo, e demonstraram certa ansiedade. No entanto, nos dias seguintes, os próprios colegas que já tinham certa experiência ajudaram os outros. A confecção de um blog de fato é muito fácil e automática.

Mas no decorrer das semanas, alguns estudantes nem sequer criaram o seu diário virtual. Em uma turma de 50 alunos , 39 fizeram seus blogs, mas 10 deixaram de fazer. Em geral, foram os mesmos 10 alunos que participaram com menos freqüência das atividades de sala. Além disso, entre os 39 que fizeram, seis criaram os diários mas não incluíram comentários, ou utilizaram-se apenas uma, duas ou três vezes. Há um caso que, no momento da consulta para o desenvolvimento da presente pesquisa, estavam fora do ar.

Quando dissemos que nossa experiência foi "inspirada" na estratégia do portfólio, isso significa que sentimos a necessidade de operar algumas importantes adaptações no conceito original, tendo em vista as contingências do curso, da disciplina Fundamentos Científicos, e observando também o caráter experimental da iniciativa. A relativa rigidez nas determinações do que os alunos deveriam necessariamente fazer foi compensada com maior sensibilidade e tolerância - e não licenciosidade - no momento da avaliação e pontuação, como será comentado a seguir. É preciso lembrar que os textos foram escritos por alunos de 10 período de Comunicação Social, e por isso nem sempre têm consolidados as técnicas de redação básicas da profissão. O próprio professor sugeriu, em conversas particulares, que estes alunos se esforçassem em um 
treinamento mais rigoroso em técnicas de escrita, antes mesmo que chegassem nas disciplinas de redação específicas do curso.

Em geral, os diários virtuais mostraram-se criativos e os alunos pareceram bastante motivados, já nas primeiras mensagens. A princípio, os blogs serviram para que as experiências em sala de aula fossem registradas, como em um diário tradicional.

Numa pequena pesquisa com meus colegas de sala, concluímos com dados numéricos, que a revista Veja tem tendências racistas. Em todos exemplares analisados, concluiu-se que num total de 245 pessoas colocadas na revista, entre políticos, artistas e modelos de propaganda somente 11 eram negros. Dentre esses 11, 2 eram artistas (Gilberto Gil e Milton Nascimento). Nas propagandas observa-se que os negros quase sempre não estão em destaque, e sim como coadjuvantes ou fazendo algum tipo de reverência a um branco. Coincidência ou não, o fato é que todos nós praticamos algum tipo de racismo, mesmo que inconsciente, por isso, devemos reavaliar nossas atitudes para não cometermos injustiças futuras.

Carla Moraes. <http://ka_kamoraes.zip.net>

É preciso começar das apresentações e da leitura do livro "O Corpo Fala". Como sempre, dar asas à imaginação é muito divertido, e nesta situação não pôde ser diferente, não só as representações que os colegas fizeram sobre seus capítulos como a elaboração do que foi estipulado ao meu grupo. Pudemos, aproveitando a chance, extravasar nossas vontades e idéias, mas também aprendemos muito a observar como é interessante e proveitosa a linguagem corporal. Depois deste livro passamos a reparar ainda mais (mesmo os já observadores!) que o corpo tem muito a dizer sobre o que pensamos. Podemos reforçar, quanto mais, contradizer o que dizemos e pensamos com reações incontroláveis. Impaciência, descontentamento, interesse e mil outros sentimentos que demonstramos mesmo se perceber. E tudo isso me fascinou ainda mais com a amplitude da comunicação.

Thassiana Macedo. <http://www.devaneiosthassianos. blogger.com.br>

Uma das aulas mais interessantes que já vi. Tratou basicamente sobre a Propaganda Subliminar, um assunto extremamente polêmico. $\mathrm{O}$ ser humano tem dois tipos de visões: consciente e a inconsciente, é exatamente nessa última que a mensagem subliminar vai afetar. Vimos também que o mais importante numa imagem é o contraste da figura principal e seu fundo, sem essa interação a imagem ficará sem sentido e de difícil interpretação. Vimos várias imagens interessante sobre ilusão de ótica, percebendo que o olho tende a criar um padrão único para as coisas.

Bruno Marcório. <http://www.brunomarcorio. weblogger.terra.com.br $>$

Fotonovela - o professor da disciplina propôs um trabalho ousado em curto tempo. Ficou definido que faremos um trabalho de fotonovela em 12 quadrinhos, que deverão seguir os 12 passos da "Jornada do Herói Mitológico" (Christopher Vogler). Em cada fotografia devemos observar as ações do corpo dos personagens com base nos conceitos do livro "O Corpo Fala" (Pierre Weil e Roland Tompakow). Por fim o trabalho ainda deve trazer mensagens subliminares.

Luiz Carlos Florentino. <http://luizjornalismo.zip.net>

Começamos com Cráudia, chicrete.... "Que isso tá errado!" Mas como nosso professor André é um cara que gosta de causar polêmicas em suas aulas, com temas bastante diferentes nos prende a atenção de uma maneira que o assunto apesar de muito doido faz sentido. Então ele pega e fala que falar assim também é "corretíssimo" pois cada um e cada região tem sua lingüística. Como sempre bastante comentários do assunto e deu pra pegar a mensagem.

Galera até mais e valeu!!!!

Luiz Guilherme. <http://guigaespigar.weblogger. terra.com.br/index.htm $>$

Esse "registro obrigatório" é muito importante para os processos de aprendizagem, e até aí não há nenhuma novidade. No entanto, o fato de saberem que esses textos poderiam ser lidos pelos colegas (impressão evidenciada em locuções do tipo: Galera até mais e valeu!!!) trouxe uma responsabilidade especial na redação e exposição das idéias - aprendizado crucial para um comunicador social. Mas apesar da orientação explícita para que os textos fossem escritos sem as licenças do "internetês", algumas vezes os alunos se empolgavam. Em geral, considerando os objetivos do portfólio, algumas transgressões foram toleradas - mas não sem uma orientação bem clara sobre a obrigação de escrever corretamente, de revisar o texto e de expor as idéias com coerência: 
O tema do nosso trabalho era maio de 68, uma revolução estudantil q ocorreu na França onde teve confrontos entre estudantes e policiais insatisfeitos com a estrutura e a disciplina rígida acadêmica conservadora. Nossa cor VERMELHA ajudou bastante a representar o que foi a manifestação. Enfeitamos o bloco L todo com frases usadas no movimento, flores (conhecido tbem como primavera de 68) vários pontos de interrogação pra deixar as pessoas curiosas e questionassem sobre o tema, caixão representando as mortes nos confrontos, os jornais pinchados, as blusas com o desenho representando a revolução e mtas outras coisa... a colocação ainda $n$ sei pq o professor ta mto indeciso por isso qdo ficar sabendo posto aki.

Daniela. $<$ http://danickmg.zip.net/>

Essa aula mexeu com muita gente, deu o que falar, polemica etc...

Falamos que Crenca é cultura, Religiao é crenca, entao religiao e cultura..isso deu no que falar.. significa que Deus é uma criacao nossa??? pense bem???

$\backslash$ quanto ao que as coisas sao inventadas, podemos chamá las do que bem a gente quiser, mas a sociedade impos limites para isto...

esta aula fio muito loka...

Diego Rafael Borges Oliveira. <http:// diegoliveirablog.zip.net/>

olaaaaaaaaaá "comunicólogos"!

E ai semana passada o prof tava viajando...que folga...

Mas essa semana tivemos duas aulas boas demais: na terça falamos de INDÚSTRIA CULTURAL XCULTURA DE MASSA. Gostei, achei interessante, tipo o que a mídia, o consumismo pode fazer com as pessoas com seus supostos padrões de tudo...Tivemos uma aula de Sociologia na quinta que completou a aula do professor André. Ah, achei bacana também aquele parada sobre IMERSÃO > EMERSÃO > INSERÇÃO, a maioria das pessoas ficam nessa tal "imersão não sei por comodismo ou por livre arbítrio mesmo, só sei que esse negócio de Emersão também é bem "doido", o que eu gostei mesmo foi da Inserção onde se pode (se a sociedade capitalista deixar) colocar nossas ideologias na prática.

Depois teve um filme falando também sobre consumismo. Não entendi ele ainda muito bem não mas semana que vem o prof vai falar sobre isso...

Agora vou dormir pq também sou vitima do "sistema". Amanhã falo sobre as matérias do "Observatório" que é bem legal... até amanha bjim pra todos... Mari

Marilene Conrado. <http://mariconrado.blog.uol.com.br>
O registro on-line implica necessariamente que, a cada atualização, o aluno vai reler, ou no mínimo passar os olhos nos temas da disciplina, o que reforça a compreensão de seu processo de aprendizagem. Além disso, a possibilidade de ler o diário do colega sugere uma ligação de idéias, de forma que algumas dúvidas que porventura ainda tenham com relação a algum aspecto do conteúdo possam ser resolvidas com algum insight de um colega. Outro fator importante é que o professor tem uma medida interessante para notar até que ponto as discussões em sala foram bem orientadas. Quando alunos registram uma reflexão incoerente, ou equivocada, é possível voltar o tema em sala de aula.

É preciso observar que, tendo em vista os objetivos e as orientações para a confecção dos blogs, os alunos não se sentiram forçados a escrever uma monografia para cada aula. Os comentários são leves, ágeis e acabaram funcionando mais como um registro superficial do conteúdo do que um trabalho aprofundado - trabalhos estes que são aplicados nos momentos presenciais, nas salas de aula. $\mathrm{Na}$ verdade, a própria linguagem do blog implica em textos curtos, dinâmicos e estruturalmente sucintos.

Alguns dos comentários concentraram-se mais em experiências emocionais do que necessariamente as questões intelectuais. No entanto, essas considerações também são muito importantes para a experiência pedagógica, e têm grande valor.

Adorei as palestras que aconteceram durante o decorrer da semana. Foram muito criativas serviram como uma das "luvas" que eu precisarei pra o meu futuro.

O bloco L estava demais, pelo menos eu adorei trabalhar com outras pessoas que eu nunca tive nenhum contato, foi $\mathrm{d}+$.

Fabíola. < http://www.fabiolabeatrizpp.weblogger. terra.com.br>

Assistimos ao documentário Surplus. adorei, achei excelente, um jogo de imagem e som fabuloso...e fala de muita coisa importante, você assiste e quer sair quebrando tudo, mudando o mundo. a menina de 
Cuba que vivia num regime socialista e quando foi para os E.U.A. não sabia o que fazer primeiro, só ia no Mc'Donalds, assistia TV... é a dura realidade mundial.

Katrine. < http://www.katty03pp.weblogger.terra. com.br/index.htm>

\section{9/10 OOO LIVRO COMPLICADO...CAPÍTULO 1}

Bom...foi explicado o capitulo 1 do livro História das teorias da comunicação...a sociedade organismo.... bom o nome ja diz tudo.... para uma sociedade melhor organizada e em total sincronia, os meios de comunicação deveriam agir como ligações do organismo do corpo humano... bem fácil de entender com o André explicando... já lendo o livro da um trabalhinho a mais.... ô livrinho milongueiro..... bom....é isso ae.

Leopoldo. <http://lobotomiainformatizada.zip.net>

Alguns registros falaram sobre os interesses intelectuais despertados nos alunos, com ou sem relação com a disciplina. Esses comentários também foram considerados na avaliação, pois acreditamos que o objetivo do portfólio também é registrar essas primeiras inquietações acadêmicas.

Quero escrever sobre a relação próxima que existe entre linguagem e poder. Atualmente conseguimos identificar isso com muita transparência, especialmente no meio de tanta informação que corre nos veículos de comunicação. Meu primeiro objeto de estudo será a linguagem manuscrita. Quero tentar entendê-la, tentar interpretá-la e quem sabe conseguir provar que a linguagem manuscrita está diretamente ligada à expressão de poder. É notável a preocupação de pessoas em condições de submissão em fazer com que a letra seja entendida, decifrada. Em contrapartida a letra manuscrita de pessoas em situação de domínio não apresenta tanta preocupação formal. $\mathrm{O}$ objetivo dessa análise especificamente é mostrar como o desejo do poder, ou da expressão de poder inicia já na expressão da escrita. É como se os médicos (por exemplo) numa tentativa de tornar claro o domínio e autonomia de sua ação no ato de prescrever uma receita não desse a mínima importância para a forma de se escrever. Preciso reunir mais recursos para esse primeiro momento do estudo.

Júlio César Prado. < http://jpradoblog.zip.net>

Não foram todos os alunos que visitaram regularmente o sítio do Observatório da imprensa, ou que ficaram atentos para estabelecer ligações com outros sítios de interesse complementar aos assuntos discutidos em sala de aula. Mas os que fizeram gostaram da indicação.

\section{QUEM LUTOU PELALIBERDADE DE IMPRENSA}

Achei bacana a matéria que escolhi essa semana, bacana modo de dizer pois os jornalistas na década de 70 não podiam falar nem escrever nada que ía contra o governo e bons costumes da época, os que arriscavam eram mortos ou exilados, muitos nem eram encontrados mais.

E acha que hoje em dia mudou? Que nada somente "camuflou" a liberdade de imprensa lembram do TIM LOPES foi executado por "falar demais", foi uma grande perda para comunicação brasileira, mas mesmo assim continuam na luta mesmo sendo C-EN-S-U-R-A-D-O-S.

SERÁ QUANDO PODEREMOS FALAR DE FATO COM LIBERDADE, não essa imprensa medíocre e irresponsável, mas sim o bom caráter, pois através dela que move o mundo visual e escrito.

blz...boa semana pessoal. Mari

Marilene Conrado < http://mariconrado.blog.uol. com.br/>

\section{Conclusões}

Ao desenvolver suas reflexões sobre a contribuição do portfólio para a avaliação formativa, Villas Boas (1998) - que prefere traduzir o termo portfólio para "pastas avaliativas" - defende que essa modalidade de avaliação deve ser composta das produções selecionadas pelos próprios alunos ou pelo professor, e também de seus comentários sobre o progresso e as carências na formação que eventualmente o registro torna explícito.

Assim constituída, ela [a pasta avaliativa] tem a grande vantagem de permitir o acompanhamento do trabalho pelo aluno e pelo professor, o que representa a realização de uma avaliação conjunta, que fortalece os laços entre ambos e, em conseqüência, torna-os parceiros do processo. (VILLAS BOAS, 1998, p. 188).

De fato, os alunos cobram do professor que este deixe registrados seus comentários no diário virtual. Essa presença sistemática é muito importante. Eles se sentem motivados e percebem que os blogs são verdadeiramente importantes quando o educador demonstra que se interessa em visitálos periodicamente. A estratégia utilizada foi, como explicitado acima, realizar três vistorias de 
surpresa, com fins avaliativos. Mas foi igualmente importante deixar mensagens nos blogs e fazer comentários orais sobre os trabalhos em sala de aula, incentivando os alunos a ler a reflexão no blog de um colega, etc.

Em uma experiência com outra turma, realizada no primeiro semestre de 2005 na disciplina Comunicação \& Cultura Brasileira, o professor utilizou-se de trechos das próprias reflexões dos alunos para elaborar uma avaliação do tipo "verdadeiro e falso". Os parágrafos retirados dos blogs dos estudantes exemplificavam as opções verdadeiras, e novas frases foram criadas pelo professor para assinalar as falsas. Os alunos que reconheceram suas frases no momento da avaliação mostraram-se motivados em perceber que suas anotações estavam boas o bastante para servir de modelo para avaliação.

O estímulo para que eles deixassem mensagens nos blogs dos colegas não surtiu efeito considerável. Se eles se visitaram, o fato é que poucos registraram comentários. Os endereços dos diários virtuais da turma estavam disponíveis permanentemente no sistema interno on-line da Uniube, mas isso não bastou para provocar uma visitação maciça. Essa é uma questão a ser repensada, pois essa troca é fundamental para o processo. Outro problema foi a interrupção de atualizações de praticamente a totalidade dos alunos nas últimas semanas do semestre. Os resultados dos trabalhos sobre História das Teorias da Comunicação, por exemplo, não foram registrados nos blogs. Talvez devido ao cansaço de final de semestre, unido ao acúmulo de trabalhos e avaliações finais. Na verdade, os alunos em geral não reproduziram seus trabalhos de sala nos blogs, provavelmente devido à dimensão dos textos e, como relatado por alguns alunos, a alguma dificuldade em incluir imagens, devido às limitações de espaço do próprio sistema do blog.

Tendo em vista as especificidades no desenvolvimento de uma avaliação inspirada na estratégia do portfólio adaptada às contingências do diário virtual na Internet, a experiência parece ter surtido os seguintes efeitos principais:

a) A maioria dos alunos de Comunicação Social, e sobretudo aqueles que não conheciam as ferramentas de confecção de blogs, familiarizaramse com a lógica do diário virtual no decorrer do semestre e mostraram-se interessados em explorar as possibilidades de sua linguagem.

b) $\mathrm{O}$ registro e a atualização sistemática dos blogs contribuíram para que os alunos tomassem consciência da progressão de seu desenvolvimento intelectual em relação às discussões da disciplina. No final do semestre, cada um construiu praticamente um resumo em tópicos de alguns dos principais assuntos tratados em sala de aula.

c) $\mathrm{O}$ diário virtual proporcionou uma oportunidade a mais para que os estudantes realizassem reflexões complementares sobre sua experiência universitária, suas indagações acadêmicas e inquietações intelectuais. $\mathrm{O}$ produto final foi interessante também como um diário que registrou suas vivências emotivas e existenciais no curso durante o semestre.

d) Apesar da pouca interatividade entre os alunos observado nesta experiência em particular, o blog acadêmico parece ter o potencial de promover maior discussão teórica entre os colegas.

A adaptação do portfólio para o blog não parece capaz, entretanto, de substituir processos de avaliação mais completos, como o próprio portfólio impresso. O blog possui limitações estruturais, tais como questões relacionadas à extensão do texto e à capacidade de armazenamento de informação - características próprias dessa forma de linguagem digital. Não obstante, além de sua dimensão motivacional, o blog parece funcionar eficientemente como uma instância complementar de organização dos estudos e de conscientização do processo intelectual.

A partir de 2006, com as mudanças no projeto pedagógico e no currículo do curso de Comunicação 
Social da Uniube e a consequente eliminação das atividades não-presenciais da disciplina Fundamentos Científicos da Comunicação, a estratégia dos blogs foi incorporada ao processo de avaliação regular. A grande novidade deste ano foi a orientação no sentido de que todos confeccionassem os blogs em um único provedor gratuito (www. blogger.com), pois assim conquistaríamos maior padronização de linguagem e maior agilidade na geração de redes entre os colegas. Mas esta é uma experiência ainda em andamento, cujos resultados poderão ser verificados em um outro trabalho. Podemos adiantar que alguns blogs, como o da aluna Telma Reis (http://glicapp.blogspot.com), evidenciam a potencialidade dessa estratégia para o estímulo ao registro do desenvolvimento intelectual dos alunos.

\section{Referências}

BRASIL. Ministério da Educação. Diretrizes curriculares para os cursos de graduação. Brasília: SESu/MEC, 2004. Disponível em: <http://portal. mec.gov.br/sesu/index.php?option=content\&task $=$ view $\& i d=430 \&$ Itemid=420 $>$. Acesso em: 15 jul. 2011.

FONSECA, André Azevedo da. Plano de ensino: fundamentos científicos da comunicação. - código: 90157. Uberaba: Universidade de Uberaba (Uniube). Curso de Comunicação Social. Habilitação Jornalismo. 2o semestre de 2005. [fotocópia].

FREIRE, Paulo; SHOR, Ira. Medo e ousadia: cotidiano do professor. Rio de Janeiro: Paz e Terra, 1986.

GUSMAN, Antonio Barioni et al. Portfólio: conceito e construção. Uberaba: Instituto de Formação de Educadores. Universidade de Uberaba, 2002. [fotocópia]. $6 \mathrm{p}$.

HERNANDEZ, Fernando. Cultura visual: mudança educativa e projeto de trabalho. Porto Alegre: Artmed, 2000.

MOULIN, Nelly. Utilização do portfolio na avaliação do ensino a distância. São Paulo: Associação Brasileira de Educação Distância, 2005.
Disponível em: <http://www.abed.org.br/publique/ cgi/cgilua.exe/sys/start.htm?UserActiveTemplate $=4$ abed $\&$ infoid $=112 \&$ sid $=122 \&$ tpl $=$ printerview $>$. Acesso em: 15 jul. 2011.

VIEIRA, Vania M. O. Portfólio: uma proposta de avaliação como reconstrução do processo de aprendizagem. Revista Psicologia Escolar e Educacional, Maringá, v. 6, n. 2, p.149-153,.jun./ dez. 2002.

VILLAS BOAS, Benigna Maria de Freitas. O projeto político pedagógico e a avaliação. In: VEIGA, Ilma Passos Alencastro; RESENDE, Lúcia Maria Gonçalves de (Org.). Escola: espaço do projeto político-pedagógico. Campinas: Papirus, 1998. p. 179-200. 